\title{
Preparation and Characterization of Soybean Straw Activated Carbon by Zinc Chloride
}

\author{
Xu Zhong, Zhao Dan
}

(Department of Environmental Engineering, College of food Engineering, Harbin university of Commerce, Harbin 150076, China)

Keywords: soybean straw, activated carbon, zinc chloride, activation

\begin{abstract}
The activated carbon was prepared from soybean straw by activation of zinc chloride. Porosity characterstics were determined from the analysis of $\mathrm{N}_{2}$ adsorption isotherms using BET and $\mathrm{BJH}$ method. Microstructure of the sample was examined using a scanning electron microscopy. The results showed that the best sample of activated carbon was obtained under the conditions: the impregnation ratio of 3 ; impregnation time of $20 \mathrm{~h}$, activation temperature of $500^{\circ} \mathrm{C}$ and activation time of $90 \mathrm{~min}$. The iodine adsorption value, methylene blue adsorption value and phenol adsorption value were $750.67 \mathrm{mg} / \mathrm{g}, 168.01 \mathrm{mg} / \mathrm{g}$ and $205.36 \mathrm{mg} / \mathrm{g}$, respectively. Activated carbon has high BET surface area $\left(1526.54 \mathrm{~m}^{2} / \mathrm{g}\right)$ and whole pore volume $\left(0.876 \mathrm{~cm}^{3} / \mathrm{g}\right)$ with average pore diameter of $3.413 \mathrm{~nm}$.
\end{abstract}

\section{Introduction}

As adsorbent material, porous activated carbon has a wealth of pore structure and high specific surface area and pore volume, widely used in environmental medicine, food and other fields ${ }^{[1,2]}$. Traditional activated carbon preparation raw material mainly coal, timber, etc ${ }^{[3,4]}$. With the depletion of activated carbon production costs and increasing disposable resource, it is an urgent need to find new cheap preparation of activated carbon resources, so more and more people pay attention to cheap agricultural waste as raw material for preparing activated carbon ${ }^{[5,6]}$. Our country is agricultural country and it has rich resource of crop straw. Tobacco stem ${ }^{[7]}$, flower stalk, corn stalk of wheat straw, rice straw and other wastes as raw material to the study of the preparation of activated carbon has been reported in recent years ${ }^{[8-10]}$, while the research of the preparation of activated carbon with the soybean straw as raw material has yet to see the detailed report. As soybean straw resource was rich, the preparation of activated carbon with it can avoid air pollution and also provide a new way for the utilization of soybean straw. Because zinc chloride activation method has so many advantage such as a low activation temperature, activated carbon and high yield, etc. we used soybean straw as raw soybean straw to prepare activated carbon ,zinc chloride as an activator, that reduced the cost of production of activated carbon, but also achieved the integrated utilization of waste.

\section{Experiment}

\subsection{Experimental materials.}

With abandoned soybean straw as raw material, the element analysis of the content of $\mathrm{C}, \mathrm{H}, \mathrm{N}$ in straw were $44.53 \%, 0.40 \%$ and $5.83 \%$, respectively. Experiments with zinc chloride, iodine, potassium iodide, methylene blue, phenol, hydrochloric acid were of analytical grade, supplied by Shanghai Chemical Reagent Co..

\subsection{Experimental apparatus}

The main instrument used in the experiment were specific surface area analyzer, model Quadrasorb SI-KR/MP, Quantachrome Instruments Inc. USA; Fourier transform infrared spectrometer, model PE-100, U.S. PE firm ;Scanning electron microscope, model FEI Sirion, the Netherlands, Philips; Elemental analyzer, model Flash EA1112, USA Thermo Fisher Scientific Company; Box-type resistance furnace, SXZ-5-12A type, Ltd. Tianjin Central laboratory furnace. 


\subsection{Experimental content}

\subsubsection{The preparation of soybean straw activated carbon}

Soybean straw were dealed with by washing, drying, crushing through a 60 mesh sieve, then zinc chloride solution and soybean straw material were mixtured by a certain ratio (zinc chloride and soybean straw mass ratio) and dry after some dipping time. Activated carbon was prepared by using the limiting oxygen straw temperature carbonization. The dried soybean straw was put into porcelain crucible, activated at a temperature of $300-700{ }^{\circ} \mathrm{C}$, holding a certain time and then cooled, pickled, washed until neutral, dried and standby .

\subsubsection{Soybean straw activated carbon adsorption performance test}

The measured of activated Carbon Iodine soybean straw was reference to GB/T 12496.8-1999, methlene blue adsorption Asia reference to GB/T 12496.10-1999, phenol adsorption reference to GB/T 12496.12-1999 determined.

\subsubsection{Characterization of soybean straw activated carbon}

The specific surface area of activated carbon soybean straw, pore volume and pore diameter were measured by Quadrasorb SI-KR/MP type surface area analyzer, specific surface area of activated carbon was measured by the BET, activated carbon pore diameter and pore volume were obtained by the BJH method. Determination of activated carbon $\mathrm{C}, \mathrm{H}, \mathrm{N}$ element content was measured by Flash EA1112 Series elemental analyzer. The analysis of activated carbon surface chemical functional groups were obtained by fourier transform infrared spectrometer, potassium bromide tabletting method. Microscopic surface morphology of active carbon were observed by using FEI Sirion type of scanning electron.

\section{Results and discussion}

\subsection{Analysis of preparation process conditions of activated carbon}

The effection of impregnation ratio, dipping time, activation temperature and activation time on the properties of activated carbon adsorption were showed in Figure 1 (a) and (b) (c) (d) respectively. Zinc chloride have catalytic dehydroxylation and dehydration effect, making the raw material of hydrogen and oxygen release in the form of water vapor, thus forming microporous structure, and impregnation ratio is small, low activation temperature, activation time and the immersion time is short, the raw material of zinc chloride activation insufficient to generate enough porosity. Conversely, for raw materials of zinc chloride activation degree increase, the degree of erosion overactive activator for raw materials will increase, carbon ignition loss increase, causing pore diameter expanding, and pore structure was destroyed, the adsorption value decreased, Taking all factors that more appropriate preparation conditions of activated carbon impregnated ratio was 3 , dipping time was $20 \mathrm{~h}$, the activation temperature was $500{ }^{\circ} \mathrm{C}$, activation time was $90 \mathrm{~min}$.
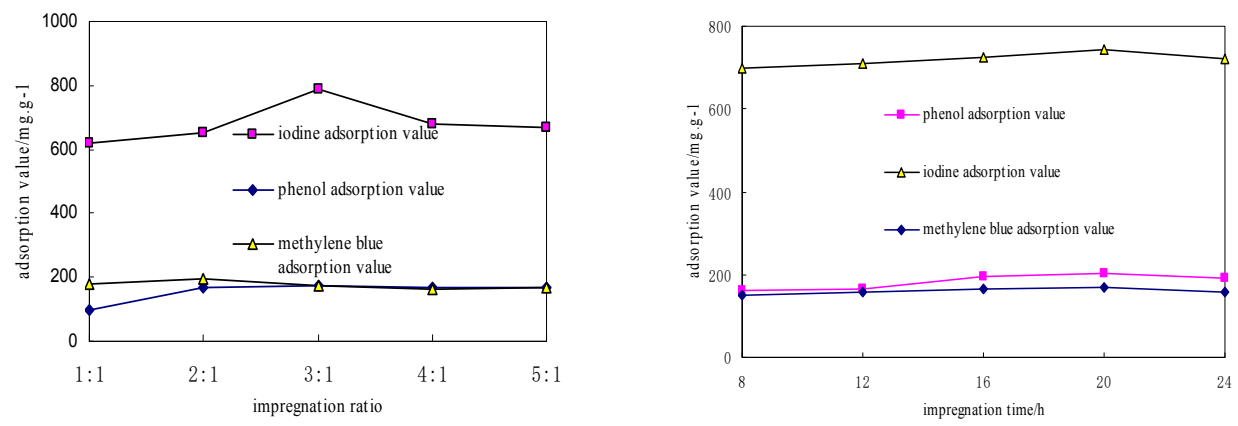

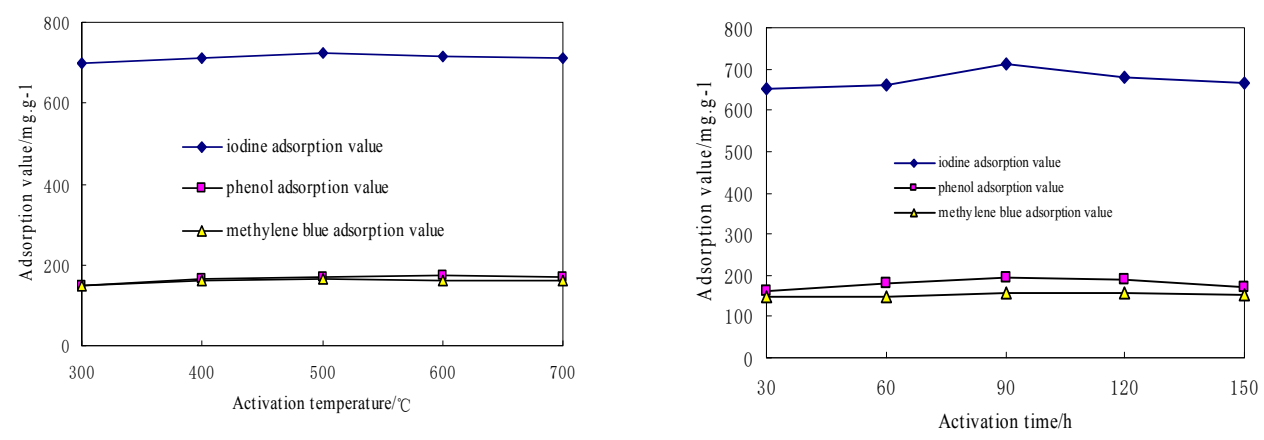

Fig 1 Effects of impregnation ratio impregnation time、 activation temperature and activation time on iodine, methylene blue and phenol adsorption

\subsection{Characterization of soybean straw activated carbon}

\subsubsection{Characteristics of specific surface area and pore structure}

The soybean straw activated carbon at $77 \mathrm{~K}$ under nitrogen isothermal adsorption - stripping was showed in Figure 2. As can be seen from Figure 2 nitrogen adsorption - desorption isotherms are typical type 1 curve, and the adsorption-desorption isotherms between a closed curve exists a slight hysteresis loop, indicating the presence of a large amount of activated carbon in the porous structure and pore structure ${ }^{[13]}$. The figure 3 pore size distribution curve also shows that the soybean straw activated carbon pore size distribution is relatively uniform and concentrated, mainly distributed in 2 to $10 \mathrm{~nm}$.

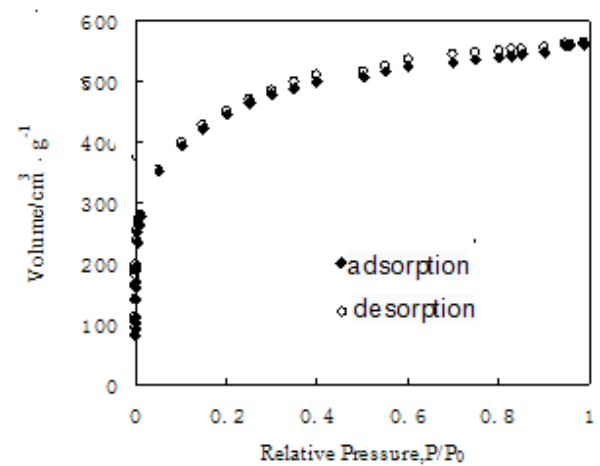

Fig.2 Adsorption-desorption of nitrogen of activated carbon activated carbon

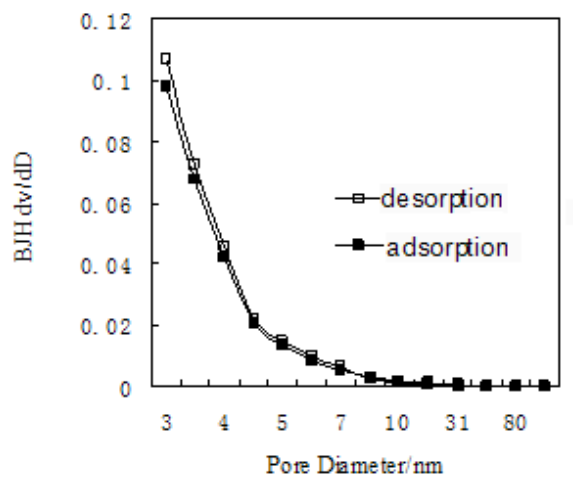

Fig.3 pore size distribution of

According to figure 2, figure 3, combining with the BET and BJH theory to calculate the optimum technological conditions of the specific surface area of activated carbon, entrance and aperture as shown in table 1. As can be seen specific surface area of activated carbon become bigger after activation treatment showed that activated carbon structure changed after the activation, produced a large number of pores and holes in the pore structure, pore and pore volume increased, accounted for $56.7 \%$ and $43.3 \%$ of total volume, that is the reason cause the increase of the specific surface area, and activated carbon has strong adsorption ability.

Table 1 Pore volume and surface area for activated carbon

\begin{tabular}{cccccccc}
\hline Type & $\begin{array}{c}\text { BET } \\
\text { Surfacearea } \\
/ \mathrm{m}^{2} \cdot \mathrm{g}^{-1}\end{array}$ & $\begin{array}{c}\text { Micropore } \\
\text { Area } \\
/ \mathrm{m}^{2} \cdot \mathrm{g}^{-1}\end{array}$ & $\begin{array}{c}\text { External } \\
\text { Surfacearea } \\
/ \mathrm{m}^{2} \cdot \mathrm{g}^{-1}\end{array}$ & $\begin{array}{c}\text { Whole } \\
\text { Volume } \\
/ \mathrm{cm}^{3} \cdot \mathrm{g}^{-1}\end{array}$ & $\begin{array}{c}\text { Micropore } \\
\text { Volume } \\
/ \mathrm{cm}^{3} \cdot \mathrm{g}^{-1}\end{array}$ & $\begin{array}{c}\text { External } \\
\text { Volume } \\
/ \mathrm{cm}^{3} \cdot \mathrm{g}^{-1}\end{array}$ & $\begin{array}{c}\text { Pore Diameter } \\
\text { Dv(d) } \\
/ \mathrm{nm}\end{array}$ \\
\hline Acticarbon & 1526.54 & 981.10 & 545.44 & 0.876 & 0.472 & 0.404 & 3.413
\end{tabular}

\subsection{SEM analysis}

Soybean straw and soybean straw activated carbon materials were observed by scanning electron microscopy, the results were shown in Figure 5 (a), (b). 

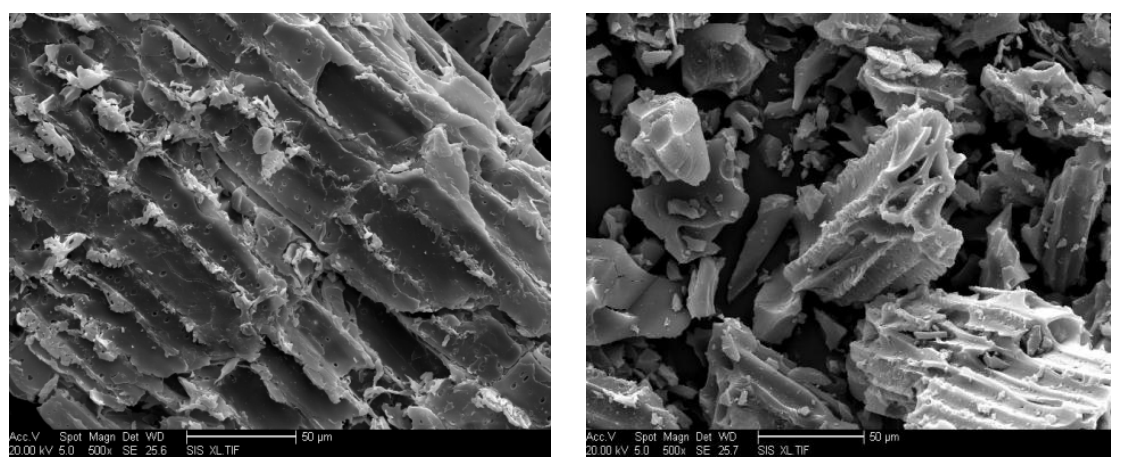

Fig. 4 SEM of soybean straw and activated carbon

Observation of SEM diagrams can be found that the appearance of the soybean straw materials show close shape structure, After activator soaking pretreatment and carbonized ,straw by closely block broken down into small block and formation of different sizes, shapes of different pore structure in a small block surface, developed pore shows that activated carbon has good adsorption performance, but also show that zinc chloride activation of straw material has good pore function.

\section{Conclusion :}

(1) appropriate conditions for Preparation of soybean straw activated carbon with zinc chloride as activator was: impregnation ratio was 3, dipping time was $20 \mathrm{~h}$, activation temperature was $500{ }^{\circ} \mathrm{C}$, the activation time was $90 \mathrm{~min}$.

the iodine adsorption value of activated carbon, methylene blue adsorption value and phenol adsorption were $750.67 \mathrm{mg}, 168.01 \mathrm{mg} / \mathrm{g} / \mathrm{g}$ and $205.36 \mathrm{mg} / \mathrm{g}$ under the condition, specific surface area, total entrance and average pore diameter were $1526.54 \mathrm{~m}^{2} / \mathrm{g}, 0.876 \mathrm{~cm}^{3} / \mathrm{g}$ and $3.413 \mathrm{~nm}$.

(2) SEM showed that there are a lot of soybean straw charcoal particle sizes, shapes and different pore structure indicated that the higher adsorption capacity.

\section{References}

[1]. BAO Jin-mei, LING Qi, LI Rui. Adsorption Mechanism of Activated Carbon and Its Application in Water Treatment. Sichuan environment . 2011,30(1):97-100.

[2]. HE Zhi-li, HE Zhi-xia,CHEN Rui-qing. Modified activated carbon adsorption performance of fluorine ion in aqueous solution. Journal of wuhan university of engineering. 2011,39(30):653-655.

[3]. XIE Xin-ping,MENG Zhong-lei,JINANG Jian-chun et al. Preparation and characterization of activated carbon from eucalyptus sawdust with phosphoric acid. journal of northeast forestry university . 2013,41(4):116-119.

[4]. CUI Dan-dan,JIANG Jian-chun,SUN Kang, Bamboo activated carbon preparation and its application as titanium dioxide loader. The 22nd carbon - graphite material academic conference proceedings. 2010, 30(5):57-60.

[5]. K.Jastrazb,M.Kavipriya,C.Karthika.[J].Bioresource Technology.2002,87:129-132.

[6]. S.Rengaraj,Seung-HyeonMoon,R.Sivabalan.[J].Waste Management,2002,22:543-548.

[7]. CHEN Ya-wei,MIAO Juan,WEI Xue-feng. Study on New Technology of Preparing Activated Carbon Adsorbents from Corn Stalks, 2010,36(5):69-72.

[8]. ZHAN Li-bo,PENG Jin-hui,ZHANG Shi-min et al. Research on mesoporous carbon acid activation of the tobacco rod preparation. journal of chemical industry, 2006,27(2):1-6.

[9]. SUN Li-hong,YANG Zai-fu,WU Xin-ma. Preparation and Characterization of Activated Carbonfrom Solidago Canadensis by $\mathrm{H}_{3} \mathrm{PO}_{4}$ Activation. Safety and Environmental Engineering, 2011,18(1):13-17. 
[10]. LIN L-ing,WANG Ying-gang,LEI Yang-ming et al. Preparation and performance study of the activated carbon by agricultural straw. journal of Anhui Agri.Sci. 2013,41 (5) : 2179-2180. 